\title{
Psikolojik Sermaye ve İş-Aile Yaşam Çatışması İlişkilerinin İncelenmesi
}

DOI: 10.26466/opus.563221

\author{
Selçuk Demir* \\ * Dr., Milli Eğitim Bakanlığı/ Hatay/ Türkiye \\ E-Posta: selcukdemirs3@gmail.com \\ ORCID: 0000-0003-2904-6443
}

\section{Öz}

Bu çalışma; öğretmenlerin sahip oldukları psikolojik sermayenin, iş-aile ve aile-iş çatışması ile ilişsisini ortaya çıkarmak amacıyla yapılmıştır. Araştırma, korelasyonel model kullanılarak tasarlanmıştır. Araştırmanın evrenini, Hatay ilinin Antakya ilçesinde 2018-2019 eğitim-öğretim yllında ilkokul, ortaokul ve liselerde görev yapmakta olan öğretmenler oluşturmaktadır. Araştırmanın örneklemi ise bu okullardaki 346 öğretmenden oluşmaktadır. Araştırmanın verileri, öğretmenlerin psikolojik sermayesini ölçmek için "Psikolojik Sermaye Ölçeği" ve iş-aile yaşam çatışmasım öllçmek için "İ̧̧-Aile Yaşam Çatışması Ölçeği" kullanılarak toplanmıştır. İş-aile yaşam çatışması ölçeği, iş-aile ve aile-iş çatışması olmak üzere iki alt ölçekten oluşmaktadır. En iyi uyum değerlerine sahip ölçüm modelinde, araştırma değişkenlerinin birbirleriyle istatistiki açıdan anlaml ilişkilere sahip oldukları tespit edilmiştir. Yapısal eşitlik modellemesi sonuçları; öğretmenlerin sahip oldukları psikolojik sermayelerinin, iş-aile ve aile-iş çatışmalar üzerinde negatif bir etkisinin olduğunu göstermektedir. Bu araştırmanın bulgular temel alınarak, öğretmenlerin olumlu psikolojik özellikleri geliştirilerek iş ve yaşam arasında denge kurmalarına katkı sunulması önemli görülmektedir. Diğer bir deyişle öğretmenlerin güçlü ve olumlu yanlarının geliştirilmesi aracılı̆̆ıyla olumsuzluklarla başedebilmelerinin kolaylaştırılmasında fayda görülmektedir

Anahtar Kelimeler: $\quad$ Psikolojik sermaye, İ̧̧-aile yaşam çatışması, İs-aile çatışması, Aile-iş çatışması 


\title{
An Analysis about the Relationships between Psychological Capital and Work-Family Life Conflict
}

\begin{abstract}
This study has been carried out to elicit the relationship between teachers' psychological capital and workfamily and family-work conflicts. This research has been designed by using correlational model. The universe of this research has been consisted of teachers that have been working at the primary, middle and high schools in Antakya district of Hatay province in the 2018-2019 academic year. The sampling of this study has been consisted of 346 teachers working at these schools. The research data have been gathered by employing "Psychological Capital Scale" to measure teachers' psychological capital and "Work-Family Life Conflict Scale" to measure work-family life conflict. Work-family life conflict scale has consisted of two sub-scales that are work-family and family-work conflicts. In the measurement model with best fit values, it has been ascertained that research variables have statically meaningful relationships with each other. The results of structural equation modeling have denoted that psychological capitals of teachers have negative effects on work-family and family-work conflicts. Based on the findings of this research, it has been seen crucial to contribute to the balance between work and life by improving positive psychological characteristics of teachers. This is all to say, it is worthwhile to facilitate teachers' abilities to cope with negativities through development of strong and positive aspect.
\end{abstract}

Keywords: Psychological capital, Work-family life conflict, Work-family conflict, Family-work conflict. 


\section{Giriş}

Her geçen gün değişen hayat koşulları ile birlikte çalışanların yoğunlukları da artmaktadır. Artan yoğunluk, çalışanların iş ve yaşam dengelerini etkilemektedir. Çalışanların, işlerindeki sorumluluklardan dolayı ailelerini ya da ailelerindeki sorumluluklardan dolayı işlerini yerine getirmeleri zorlaşmaktadır. Özellikle öğretmenlik mesleğinin, okulla sınırlı kalmadığı düşünüldüğünde, iş-aile yaşam dengesinin bozulması kolaylaşmaktadır. Öğretmenler, eş zamanlı ortaya çıkan iş ve ailedeki rolleri arasında çatışma yaşamaktadırlar. Yaşanılan rol çatışması, öğretmen özelinde daha ciddi sonuçlar ortaya koymaktadır. Öğretmenler, bu durumların doğal sonucu olarak gerginlik, stres ve tükenmişlik yaşamaktadırlar. Bu konuda Çokluk (2014) öğretmenlik mesleğinin, diğer mesleklerle kıyaslandığında daha stresli bir meslek olarak kabul edildiğini ifade etmektedir. Hock (1988) ise tükenmişlik duygusunu yaşayan önemli bir grubun da öğretmenler olduğunu belirtmektedir. Bu bağlamda öğretmenlerin, olumsuz tutum ve davranışlarla başa çıkabilmelerini sağlayıcı psikolojik kaynaklara sahip olmaları önem kazanmaktadır. Bu kaynaklardan bir tanesi de bireylerin sahip oldukları takdirde, güçlü yanlarına odaklanma ve olumlu özelliklerini öne çıkarma yoluyla olumsuz tutum ve davranışlarının azaltılmasına duygusal olarak katkı sağlayan psikolojik sermayedir.

\section{Psikolojik Sermaye}

Psikoloji bilimi, insanların olumsuz tutumlarının nedenine ve çözümüne odaklanmaktaydı (Dirican, 2015). Martin Seligman'ın 2002 yılında pozitif psikoloji kavramını ortaya koymasıyla psikoloji bilimi, insanların; daha önce ilgilenmeyi ihmal ettiği güçlü, sağlıklı yanlarına ve yaşam enerjilerine odaklanmıştır (Paşamehmetoğlu ve Yeloğlu, 2014). Pozitif psikoloji alanında yapılan çalışmalar, Luthans ve arkadaşları tarafından örgütsel davranışa uyarlanmış ve "Pozitif Psikolojik Sermaye" kavramı geliştirilmiştir (Luthans, Avey, Avolio, Norman ve Combs, 2006). Kreitner ve Kinichi $(2009$, s.147) psikolojik sermaye kavramının, insanların yanlışlarının neler olduğundan ziyade doğrularının neler olduğuna yoğunlaşan pozitif psikoloji hareketinden türetildiğini vurgulamaktadır. 
Luthans, Avolio, Avey ve Norman (2007); psikolojik sermayeyi, bireylerin pozitif psikolojik gelişme durumu şeklinde tanımlamaktadır. Çetin ve Basım (2012) psikolojik sermayenin, psikolojik bir kaynak olduğunu belirtmektedir. Kreitner ve Kinichi (2009); psikolojik sermayenin, bireylerin zihinsel ve davranışsal problemlerini önleme ve yaşam kalitelerini iyileştirmenin bir yöntemi olarak güçlü yanlarına, olumlu özelliklerine ve potansiyellerine odaklandığını ifade etmektedir. Dirican (2015) psikolojik sermayenin; çalışanların gayret göstermesine, amaca ulaşmak için azimli olmasına, zorluklar karşısında dayanıklılığına ve iyimser davranmalarına katkı sunduğunu açıklamaktadır.

Psikolojik sermaye, işyerlerine pozitif psikolojiyi taşıyan temel bir yapı olarak ortaya çıkmış olup umut, öz yeterlik, iyimserlik ve psikolojik dayanıklılık olmak üzere dört bileşenden oluşmaktadır (Luthans, Avey ve Patera, 2008, s.209; Luthans vd., 2007, s.541). Umut, bireyin başarılı olmak için azimle devam etmesi ve gerek duyulduğunda başarılı olmak için hedefe giden yola tekrar yönelmesidir (Kreitner ve Kinichi, 2009). Pozitif psikolojik sermayenin önemli bir unsuru olan umut, bireylerin performanslarını etkilemektedir (Paşamehmetoğlu ve Yeloğlu, 2014). Öz yeterlik, bireylerin amaçlarına ve istenilen sonuçlara ulaşacaklarına dair sahip oldukları inançtır (Bandura, 1997). Öz yeterlik inancı yüksek olan bireylerin, yüksek düzeyde işlevsellik gösterdikleri ve olumsuz durumlar karşısında dayanıklı oldukları, stres ve depresyondan da daha az etkilendikleri bulunmuştur (Maddux, 2002). İyimserlik, pozitif psikoloji kavramını en iyi yansıtan bileşen olarak düşünülmektedir. İyimserler; yaşadıkları olumlu deneyimleri içsel, genellenebilir ve kalıcı sebeplere bağlarken olumsuz olayları ise dışsal, geçici ve özel durumlara bağlamaktadırlar (Paşamehmetoğlu ve Yeloğlu, 2014). İyimserlik ayrıca şimdi ve gelecekte başarılı olacağına ilişkin pozitif yükleme yapmadır (Luthans vd., 2007). Dayanıklılık, başarı elde etmek için etrafını çevreleyen sıkıntı ve problemlere dayanmanın ötesinde durumunu iyileştirmedir (Kreitner ve Kinichi, 2009).

Psikolojik sermaye ve unsurlarına ilişkin sunulan bilgiler ışığında, insanların; sahip oldukları psikolojik sermayeyle genel olarak yaşamlarına daha pozitif anlamlar yükledikleri görülmektedir. Ayrıca insanlar, bu psikolojik kaynak yardımıyla kendilerine tahammül alanları oluşturmaktadır. Dirican (2015) psikolojik sermayenin, olaylar karşısında 
olumlu düşünmeye katkı sunduğunu açılamaktadır. Bu pozitif psikolojik halin, işte ve iş dışındaki rollerin eş zamanlı olarak ortaya çıkmasının neden olacağı gerginlik ve bunalım durumunu azaltacağı akla gelmektedir.

\section{İş-Aile ve Aile-İş Çatışması}

İş-aile yaşam dengesi, bireyin işinin gerektirdikleri sorumlulukları ile iş dışındaki özel yaşamından kaynaklı sorumlulukları arasındaki dengedir (Gürbüz, 2014). Bireylerin, işteki ve iş dışındaki geçirdiği zaman arasındaki ayrımın azalması, özel yaşamlarında stres ve gerginlik gibi bazı olumsuz tutumlara yol açmaktadır (Hochwarter, Ferris, Perrewe, Witt ve Kiewitz). Dolayısıyla bireyler; özel yaşamlarının, iş yaşamları tarafından zaman açısından daha sınırlı hale getirildiğini düşünmektedir. $\mathrm{Bu}$ durum ise çalışanların memnuniyetlerini azaltmaktadır (Robbins ve Judge, 2012). İşteki yoğunluktan dolayı özel yaşama zaman ayrılamadığında ya da özel yaşamdaki sorumluluklardan dolayı işteki roller yerine getirilemediğinde iş ve aile yaşamı arasında denge bozulmaktadır (Gürbüz, 2014). İş ve özel yaşam dengesinin bozulması, diğer bir deyişle kişinin bir alandaki sorumluluklarına daha fazla yoğunlaşmasıyla birlikte, iş-aile yaşam çatışması kavramını da ortaya çıkarmaktadır.

İş-aile yaşam çatışmasının, bir tür rol çatışması olduğu belirtilmektedir (Gürbüz, 2014). Rol çatışması, bireyin yerine getirmek durumunda olduğu eş zamanlı olarak ortaya çıkan rollerden birini diğerlerine kıyasla daha fazla ön plana alması şeklinde tanımlanmaktadır (Güney, 2012). Bireyler, birbirinden farklı ve uyumsuz görevlerden kaynaklı baskı altında hissetmektedirler (Özkalp ve Kırel, 2010). İş-aile yaşam çatışması ise işteki ve ailedeki rollerin aynı zamanda ortaya çımasından kaynaklı yaşanan uyumsuzluk halidir (Greenhaus ve Beutell, 1985; Parasuraman ve Simmers, 2001). İş-aile yaşam çatışması, iş-aile çatışması ve aile-iş çatışması olmak üzere iki unsurdan oluşmaktadır (Efeoğlu, 2006; Netemeyer, Boles ve McMurrian, 1996). İş-aile çatışması, iş yükü ya da işte fazla zaman geçirme gibi işle ilgili rollerin özel yaşamı engellemesidir. Aile-iş çatışması ise ailedeki sorumlulukların işteki rollere engel olmasıdır (Gürbüz, 2014). 


\section{Psikolojik Sermayenin İş-Aile ve Aile-İş Çatışması ile İlişkisi}

Önceki araştırmalar (Demir, 2018; Luthans vd., 2007), psikolojik sermayenin olumlu tutum ve davranışları geliştirdiğini ve olumsuz tutum ve davranışları ise azalttığını ortaya koymaktadır. Sen ve Hooja (2015) psikolojik sermaye ile iş-yaşam dengesi arasında pozitif ilişki bulmuşlardır. Buradan hareketle sahip olunan psikolojik sermaye ile çalışanların, iş ve özel yaşamlarını başarılı bir şekilde bölümlere ayırdıkları ya da bu ikisi arasında bir uyum elde ettikleri anlaşılmaktadır (Greenhaus ve Beutell, 1985). Wang, Liu, Wang ve Wang (2012) doktorlar üzerindeki yürüttükleri araştırmalarında, psikolojik sermayenin; iş ve aile çatışması ile tükenmişlik arasında aracılık rolünde olduğunu tespit etmişlerdir. Karatepe ve Karadas (2014) otel çalışanlarıyla yaptıkları araştırmalarında, psikolojik sermayenin; iş-aile ve aile-iş çatışmasını, iş devrini ve işe devamsızlığı azaltttığını bulmuşlardır.

\section{Araştırmanın Önemi ve Amacı}

İş-aile ve aile-iş çatışması, öğretmenlerin sadece kendilerini ve ailelerini olumsuz etkilemekle kalmayıp sundukları öğretimin kalitesini de etkilemektedir. Bu nedenle gelecek nesillerin yetiştirilmesinde büyük rolü olan eğitim örgütlerinde çalışan öğretmenlerin, iş-aile ve aile-iş çatışmalarının azaltılması önemli görülmektedir. Psikolojik sermayenin, çağımızın ciddi problemlerinden olan iş-aile ve aile-iş çatışmasına etkisine yönelik eğitim örgütleri özelinde çalışılmış bir araştırmaya rastlanmamıştır. $\mathrm{Bu}$ araştırmayla gerginlik, stres ve tükenmişlik gibi olumsuz tutumları arttıran iş ve aile çatışmasının (Mete, Ünal ve Bilen, 2014; Rubab, 2017); olumsuz etkilerinin azaltılmasına yönelik, yaşanılan olaylar karşısında olumlu düşünmeyi besleyen psikolojik bir kaynak sunulmaktadır. Bu araştırmanın amacı, öğretmenlerin sahip oldukları psikolojik sermayenin, iş-aile ve aile-iş çatışması ile ilişkisini tespit etmektir. Bu amaca ilişkin aşağıdaki hipotezler test edilmiştir:

- H1: Psikolojik sermaye, iş-aile çatışmasını negatif olarak etkilemektedir.

- H2: Psikolojik sermaye, aile-iş çatışmasını negatif olarak etkilemektedir. 


\section{Yöntem}

\section{Araştırmanın Modeli}

$\mathrm{Bu}$ araştırmada değişkenlerin birlikte değişip değişmedikleri, birlikte değişim varsa yönü ve düzeyinin incelendiği korelasyonel model (Büyüköztürk, Çakmak, Akgün, Karadeniz ve Demirel, 2012; Karasar, 2012) kullanılmıştır. Bu araştırmada; öğretmenlerin sahip oldukları psikolojik sermaye ile iş-aile ve aile-iş çatışmaları arasındaki ilişkiler incelenmiştir. Psikolojik sermayenin, iş-aile ve aile-iş çatışması üzerindeki etkisini belirlemeye yönelik her biri için ayrı bir yapısal model oluşturulmuştur.

\section{Evren ve Örneklem}

Araştırmanın çalışma evrenini, Hatay ilinin Antakya merkez ilçesinde 2018-2019 eğitim öğretim yılında ilkokul, ortaokul ve liselerde çalışan öğretmenler oluşturmaktadır. Bu araştırmada, evrendeki belirlenen bütün kümelerin eşit seçilme şansının olduğu durumda yapılan örnekleme yöntemi (Karasar, 2012), küme örnekleme yöntemi kullanılmıştır. Bu araştırmada, Antakya'daki ilkokul, ortaokul ve liseler birer küme olarak kabul edilip 49 okul rastgele seçilmiştir. Araştırmacı, öğretmenlere çalışmanın amacı ve araştırma değişkenleri hakkında bilgi vermiş ve sonrasında öğretmenlerin çalışmaya gönüllü olarak katılımları sağlanmıştır. Ölçekler, 368 katılımcıya uygulanmıştır. Ölçeklerin eksik ve özensiz doldurulması gibi nedenlerden dolayı 22 öğretmenden elde edilen veriler, geçersiz sayılmıştır. Dolayısıyla 346 öğretmenden elde edilen veriler, analize dahil edilmiştir.

\section{Veri Toplama Araçlan}

Araştırmanın verileri, sahip olunan psikolojik sermayeyi ölçmek için "Psikolojik Sermaye Ölçeği", işten kaynaklı aile ile çatışmayı ölçmek için "İş-Aile Çatışması Ölçeği" ve aileden kaynaklı işle çatışmayı ölçmek için "Aile-İş Çatışması Ölçeği" aracılığıyla toplanmıştır. Ölçekler, Likert tipi beşli derecelemeye sahiptir. 
Psikolojik sermaye ölçeği: Bu ölçek, Luthans ve diğerleri (2007) tarafından geliştirilmiş olup Çetin ve Basım (2012) tarafından Türkçeye uyarlanmıştır. Ölçek, 24 madde ve dört boyuttan (iyimserlik, psikolojik dayanıklılık, umut ve öz yeterlik) oluşmaktadır. Ölçeğin orijinalindeki dört boyutlu faktör yapısı doğrulanmıştır (Açılanan varyans $=\% 70.788$, Bartlett $=0.000, \mathrm{KMO}=0.942, \chi^{2}=147.224, \mathrm{df}=48, \chi^{2} / \mathrm{df}=3.067$, P-değeri $=0.000$, GFI: 0.930, IFI $=0.956, \mathrm{TLI}=0.939, \mathrm{CFI}=0.956, \mathrm{RMSEA}=0.077)$. Ölçeğin tamamının Cronbach's Alpha katsayısı 0.940'tır. Dört alt boyut için Cronbach's Alpha katsayıları; İyimserlik: 0.775, Psikolojik dayanıklılık: 0.807, Umut: 0.744 Özyeterlik: 0.902 şeklindedir.

İş-aile yaşam çatışması ölçeği: Bu ölçek; Netemeyer, Boles ve McMurrian (1996) tarafından geliştirilmiş ve Efeoğlu (2006) tarafından Türkçeye uyarlanmıştır. İş-aile yaşam çatışması ölçeği, iş yaşamından kaynaklanan iş-aile çatışması ve aile yaşamından kaynaklanan aile-iş çatışması olmak üzere iki alt ölçekten oluşmaktadır. Ölçek, her iki alt ölçekte de çatışma durumunu tespit etmeye yönelik 5 madde bulunmaktadır. Ölçeğin orijinalindeki iki boyutlu faktör yapısı doğrulanmıştır (Açıklanan varyans $=\% 75.866$, Bartlett $=0.000, \mathrm{KMO}=0.922, \chi^{2}=84.885, \mathrm{df}$ $=33, \chi^{2} / \mathrm{df}=2.572$, P-değeri $=0.000$, GFI: 0.954, IFI = 0.980, TLI= 0.973, CFI= 0.980, RMSEA= 0.068). Ölçeğin tamamının Cronbach's Alpha katsayısı 0.929'dur. İki alt ölçek için Cronbach's Alpha katsayıları; İş-aile çatışması: 0.928, Aile-iş çatışması: 0.909 şeklindedir.

\section{Veri Analizi}

Bu çalışmada; ölçüm hatalarını da hesaba katarak daha başarılı sonuçlar üreten Yapısal Eşitlik Modellemesi kullanılmıştır. Yapısal eşitlik modellemesi, doğrulayıcı faktör analizi ve yol analizi olmak üzere iki kısımdan oluşmaktadır (Bayram, 2013; Meydan ve Şeşen, 2015). Doğrulayıcı faktör analizi aracılığıyla çalışmadaki her bir ölçeğin faktör yapıları doğrulanmış ve bu yapıların araştırma verileri ile iyi düzeyde uyumlu olduğu görülmüştür. Ardından psikolojik sermayenin, iş-aile ve aile-iş çatışmasına ilişkin etkilerine ayrı yapısal modellerde bakılmıştır.

$\mathrm{Bu}$ araştırmada, raporlanan uyum iyiliği değerleri; $\chi 2, \chi 2 / \mathrm{sd}$, GFI, IFI, TLI, CFI ve RMSEA şeklindedir. Bu uyum iyiliği değerlerine ilişkin bilgiler Tablo 1'de sunulmaktadır (Bayram, 2013; Byrne, 2010; Kline, 2011). 
Tablo 1. Araştırmada Yararlanılan Uyum İndeksleri

\begin{tabular}{lll}
\hline Uyum Kriteri & İyi Uyum & Kabul Edilebilir Uyum \\
\hline$\chi 2 / \mathrm{sd}$ & $0 \leq \chi 2 / \mathrm{sd} \leq 2$ & $2<\chi 2 / \mathrm{sd} \leq 3$ \\
$\mathrm{p}$ & $0.05<\mathrm{p} \leq 1.00$ & $0.01<\mathrm{p} \leq 0.05$ \\
RMSEA & $0.00 \leq \mathrm{RMSEA} \leq 0.05$ & $0.05<\mathrm{RMSEA} \leq 0.08$ \\
GFI & $0.90 \leq \mathrm{GFI}<1.00$ & $0.85 \leq \mathrm{GFI}<0.90$ \\
$\mathrm{IFI}$ & $0.95 \leq \mathrm{IFI}<1.00$ & $0.90 \leq \mathrm{IFI}<0.95$ \\
TLI & $0.95 \leq \mathrm{TLI}<1.00$ & $0.90 \leq \mathrm{TLI}<0.95$ \\
$\mathrm{CFI}$ & $0.95 \leq \mathrm{CFI}<1.00$ & $0.90 \leq \mathrm{CFI}<0.95$ \\
\hline
\end{tabular}

\section{Bulgular}

Araştırma değişkenlerine ilişkin betimsel analizler (aritmetik ortalama, standart sapma, standart hata) ve korelasyon değerleri Tablo 2'de verilmektedir.

Tablo 2. Betimsel Analiz Sonuçlarn ve Korelasyon Değerleri

\begin{tabular}{lccclll}
\hline Değişkenler & $\bar{X}$ & SS & $\begin{array}{l}\text { Std. } \\
\text { Hata }\end{array}$ & $\mathbf{1}$ & 2 & 3 \\
\hline Psikolojik Sermaye & 3.797 & .554 & .029 & 1 & & \\
İş-Aile Çatışması & 2.569 & .900 & .048 & $-.112^{*}$ & 1 & \\
Aile-İş̧ Çatışması & 2.261 & .844 & .045 & $-.206^{* *}$ & $.615^{* *}$ & 1 \\
\hline
\end{tabular}

${ }^{*} p<.05,{ }^{* *} p<.001$

Tablo 2 incelendiğinde; öğretmenlerin sahip oldukları psikolojik sermayeye ilişkin algıları kısmen yüksek yüzeyde olduğu görülmektedir. Öğretmenlerin iş-aile ve aile iş çatışmasına ilişkin algıları ise kısmen düşük düzeydedir. Korelasyon matrisindeki Pearson korelasyon katsayılarına bakıldığında; psikolojik sermaye ile iş-aile çatışması (r=-.112, $\mathrm{p}<.05)$ ve aile-iş çatışması $(\mathrm{r}=-.206, \mathrm{p}<.001)$ arasında istatistiki açıdan anlamlı ve düşük düzeyde negatif ilişki bulunmaktadır.

Sahip olunan psikolojik sermaye, iş-aile ve aile-iş çatışması değişkenlerinin birbirleriyle ilişkileri, Şekil 1'deki ölçüm modelinde görülmektedir. 


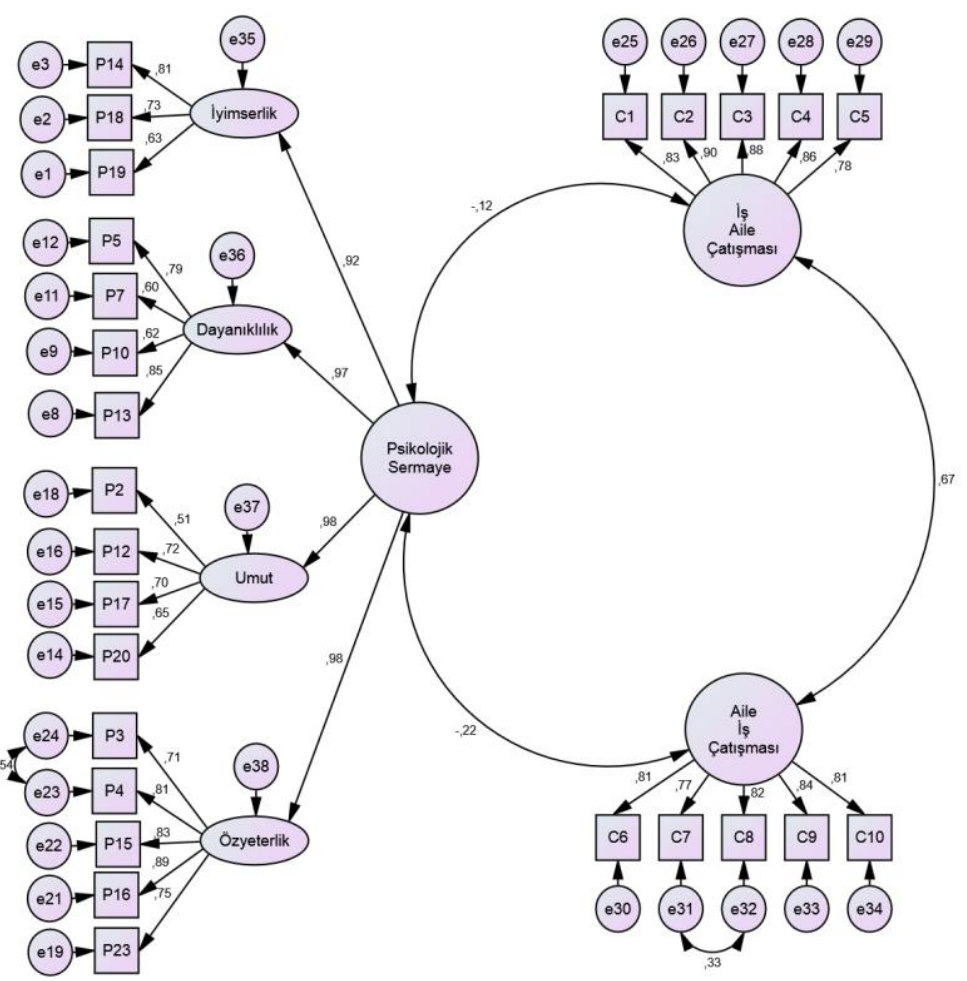

Şekil 1. Standardize Katsayılar ve Ölçüm Modeli ${ }^{1}$

Şekil 1'de ölçüm modelinde görüldügü üzere P3 ile P4 ve C7 ile C8 maddeleri arasına, maddelerin hataları arasında ilişki tespit edilmesi sebebiyle hata kovaryansları eklenmiştir. Hata varyansını ve ki-kare değerini yükseltmeleri nedeniyle P8, P22, P21, P24, P6 ve P9 maddeleri modelden çıkarılmıştır. P11 (.305) ve P1 (.309) maddelerinin standardize regresyon ağırlıkları .35 'ten küçük olduğundan modelden silinmişlerdir. Ölçüm modelindeki değişkenlerin birbiriyle anlamlı ilişkilere sahip oldukları görülmektedir. Uyum iyiliği değerlerine bakıldığında, model

${ }^{1}$ Uyum indisleri: $x 2=718.973, s d=290, x 2 / s d=2.479, p=.000, G F I=.859, I F I=.932, T L I=.923, C F I=.931$, RMSEA $=.065$ 


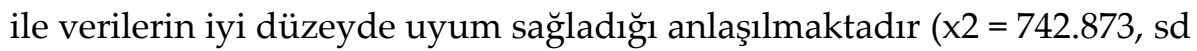
$=291, \mathrm{x} 2 / \mathrm{sd}=2.553, \mathrm{p}=.000, \mathrm{GFI}=.855, \mathrm{IFI}=.928, \mathrm{TLI}=.919, \mathrm{CFI}=.928$, RMSEA $=.067$ ).

Öğretmenlerin sahip oldukları psikolojik sermayenin, iş-aile çatışmasındaki rolüne ilişkin yapısal model Şekil 2'de görülmektedir.

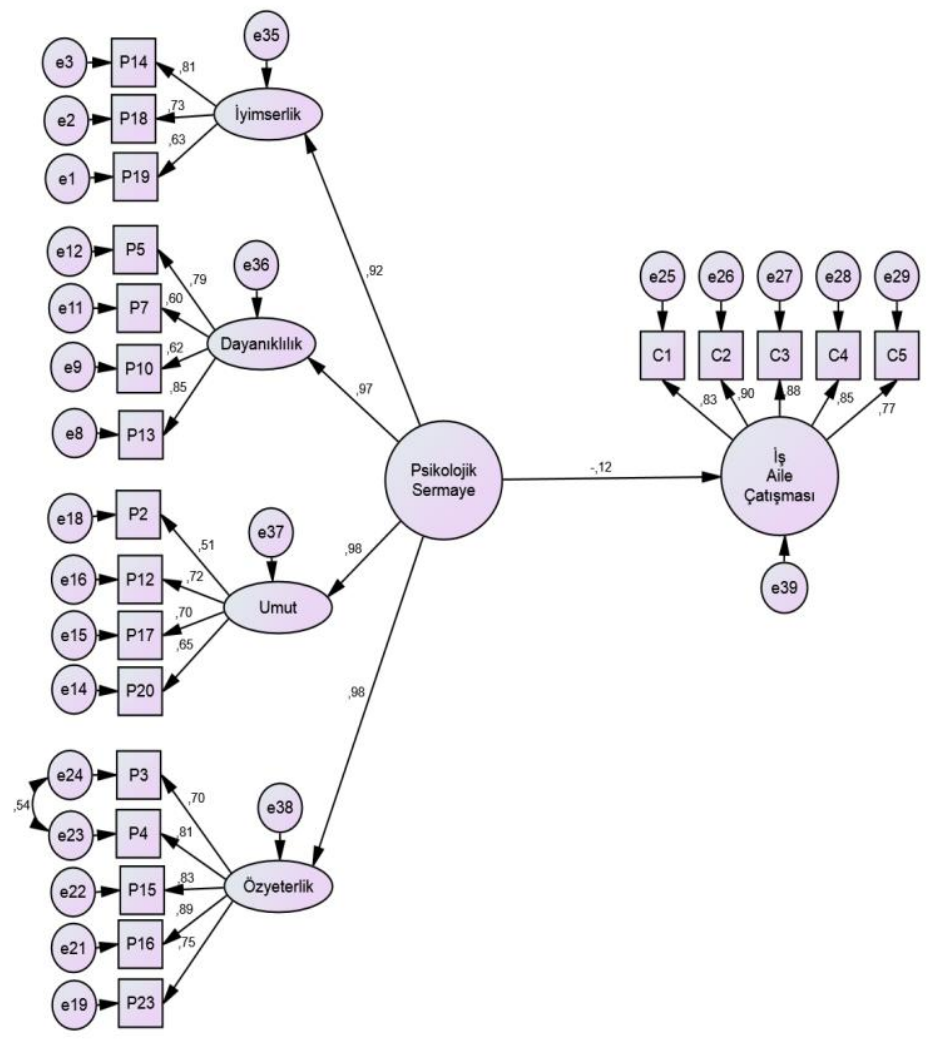

Şekil 2. Psikolojik Sermayenin, İş-Aile Çatışmasındaki Rolüne İlişkin Yapısal Model²

\footnotetext{
${ }^{2}$ Uyum indisleri: $x 2=528.115, s d=183, x 2 / s d=2.886, p=.000, G F I=.866, I F I=.930, T L I=.919, C F I=.930$, RMSEA $=.074$
} 
Şekil 2'deki en iyi uyum değerleri üreten yapısal modele göre; öğretmenlerin sahip oldukları psikolojik sermaye, iş-aile çatışmalarını negatif olarak etkilemektedir $(\beta=-.12, \mathrm{p}<0.05)$. Her 1 birimlik sahip olunan psikolojik sermaye artışı, .12 birimlik iş-aile çatışmasındaki azalışa yardımcı olmaktadır. Psikolojik sermaye düzeylerindeki artış, öğretmenlerin aileleriyle çatışma yaşamalarını azaltmaktadır. Dolayısıyla test edilen $\mathrm{H} 1$ hipotezinin doğrulandığı görülmektedir.

Öğretmenlerin sahip oldukları psikolojik sermayenin, aile-iş çatışmasındaki rolüne ilişkin önerilen yapısal model Şekil 3'te görülmektedir.

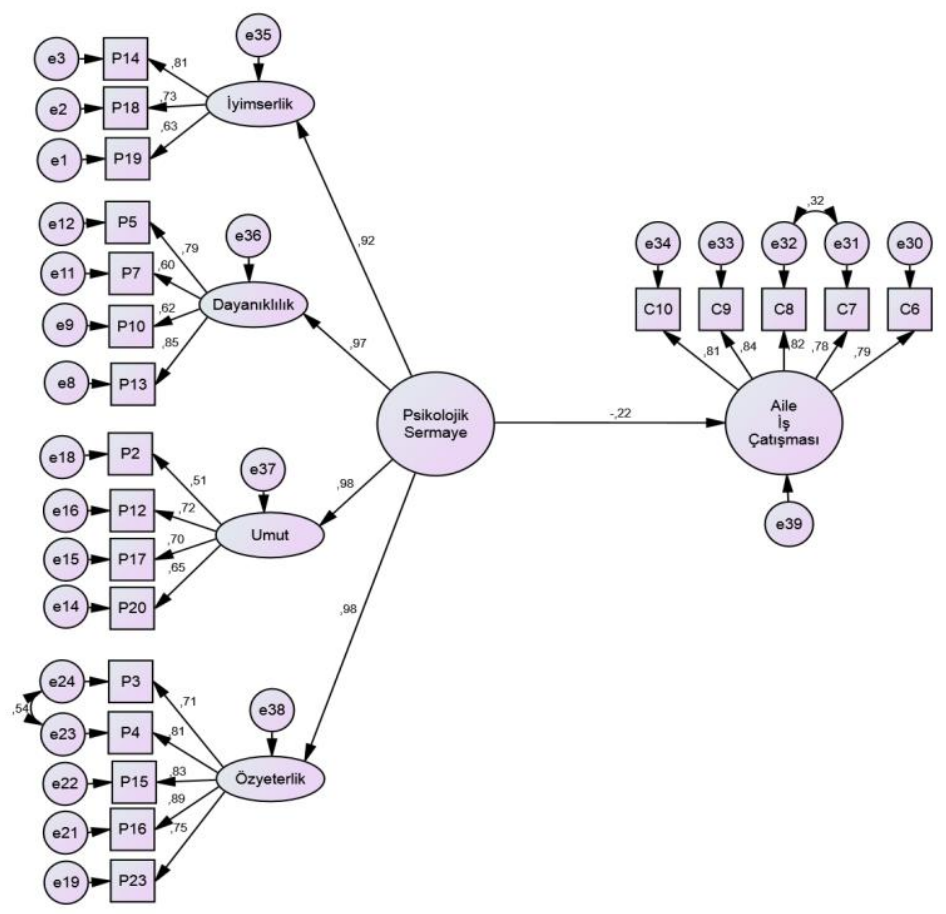

Şekil 3. Psikolojik Sermayenin Aile-İ̧ş Çatışması Üzerindeki Rolüne İlişkin Yapısal Model ${ }^{3}$

\footnotetext{
${ }^{3}$ Notlar: Uyum indisleri: $x 2=548.813, s d=182, x 2 / s d=3.015, p=.000, G F I=.862, I F I=.923, T L I=.910, C F I$ $=.922$, RMSEA $=.076$
} 
Öğretmenlerin sahip oldukları psikolojik sermaye, aile-iş çatışmasını negatif olarak etkilemektedir $(\beta=-.22$, $\mathrm{p}<0.05)$. Her 1 birimlik sahip olunan psikolojik sermaye düzeyindeki artış, .22 birim aile-iş çatışması azalışına yardımcı olmaktadır. Psikolojik sermayenin artışı, aileden kaynaklı işle çatışmayı azaltmaktadır. Dolayısıyla test edilen $\mathrm{H} 2$ hipotezi de doğrulanmıştır.

\section{Tartışma, Sonuç ve Öneriler}

Araştırmada varsayılan ölçüm modeli, psikolojik sermaye ile iş-aile ve aile-iş çatışmasının istatistiki açıdan anlamlı ilişkiye sahip olduğunu göstermiştir. Ölçüm modelinin ardından psikolojik sermayenin, iş-aile ve aile-iş çatışmasındaki rolüne ilişkin yol analizleri yapılmıştır. Öğretmenlerin sahip oldukları psikolojik sermayelerinin, iş-aile ve aile-iş çatışmasını azalttığı bulunmuştur. Diğer bir deyişle öğretmenlerin olumlu psikolojik halleri; işteki rolleri yerine getirmesini engelleyen ailedeki sorumlulukların ve ailedeki rollerin yerine getirilmesini engelleyen işteki sorumlulukların, dengeli ve uyumlu olmasına katkı sağlamaktadır.

Alanyazın incelendiğinde psikolojik sermayenin, iş doyumu (Akçay, 2012; Erkuş ve Findıkl1, 2013; Demir, 2018; Luthans vd., 2007; Luthans ve Youssef, 2004) ve örgütsel bağlllık (Çınar, 2011; Dirzyte, Patapas, Smalskys ve Udaviciute, 2013) gibi olumlu tutumsal çıtılarla pozitif ilişkili; stres (Bradley, 2014; Demir, 2018) ve tükenmişlik (Demir, 2018; Wang vd., 2012) gibi olumsuz tutumsal çıtılarla ise negatif ilişkili olduğu görülmektedir. Bu araştırmada ise psikolojik sermayenin, iş-aile ve aile-iş çatışmasını azalttığı açığa çıkarılmıştır. Sen ve Hooja (2015) araştırmalarında, psikolojik sermayenin, iş-yaşam dengesi ile pozitif ilişkili olduğunu tespit etmişlerdir. Bu bulgudan yola çıkıldığında, sahip olunan psikolojik sermayenin; kişilerin, iş ve özel yaşamlarını bölümlere ayırmalarına ya da bu ikisi arasında bir uyum yakalamalarını sağladığı anlaşılmaktadır (Greenhaus ve Beutell, 1985). Wang ve diğerleri (2012) araştırmalarında, psikolojik sermayenin; iş ve aile çatışması ile tükenmişlik arasında aracılık rolünde olduğunu tespit etmişlerdir. Karatepe ve Karadas (2014) ise araştırmalarında, psikolojik sermayenin; iş-aile ve aile-iş çatışmasını azaltmakla kalmayıp iş devrini ve işe devamsızlığı 
azalttığını ortaya koymuşlardır. Bu araştırma bulgularının, önceki araştırma bulgularıyla da desteklendiği görülmektedir.

$\mathrm{Bu}$ araştırmada sahip olunan psikolojik sermayenin, ailedeki rollerin işten kaynaklı olarak engellenmesi ve işteki rollerin ise aileden kaynaklı engellenmesi durumlarında; kişilerin, olumlu psikolojik hallerine yardımcı olduğu görülmektedir. Dolayısıyla, sahip olunan psikolojik sermaye ile kişilerin, yaşamlarındaki olaylara pozitif anlamlar yükleyebildikleri anlaşılmaktadır. Nitekim psikolojik sermayenin, kişilerin; karşılaşılan olumsuz durumlarda iyimser, sıkıntılara karşı dayanıklı, yapabileceğine inancı yüksek düzeyde ve amaçlarını gerçekleştirmede kararlı olmalarına katkı sunduğu bilinmektedir.

Öğretmenlerin iş ve ailelerinden kaynaklı rol çatışmaları yaşamalarını azaltmak için psikolojik sermayelerinin güçlendirilmesinde yarar görülmektedir. Bu kapsamda, öğretmenlerin sahip oldukları psikolojik sermayesinin geliştirilmesine yönelik, alan uzmanları tarafından öğretmenlere eğitim seminerleri düzenlenebilir. Bu yolla öğretmenlerin güçlü ve olumlu yanlarının belirlenmesi ve bu belirlenen özelliklerinden iş ve aile yaşamları arasında denge kurabilmeleri konusunda faydalanabilmeleri sağlanabilir.

$\mathrm{Bu}$ araştırmada, psikolojik sermayenin, aile-iş ve iş-aile çatışmasının her biri üzerindeki rolüne ilişkin kavramsal bir yapı ortaya konulmuştur. Bu kavramsal yapı hakkında daha detaylı bilgiler elde etmek için psikolojik sermayeyi oluşturan unsurlarla iş-aile ve aile-iş çatışması arasındaki ilişkiler incelenebilir. Bu kavramlar arası ilişkilere yönelik nedensel çözümlemeler sunulabilir. Böylelikle araştırma değişkenleri ve aralarındaki ilişkiler daha detaylı bir şekilde açıklanabilir. 


\title{
EXTENDED ABSTRACT
}

\section{An Analysis about the Relationships between Psychological Capital and Work-Family Life Conflict}

\author{
Selçuk Demir
}

National Education Ministry

Day by day, the densities of employees also increase with the changes in life conditions. Increased density affects both work and life balances of employees. It is hard to carry out their work due to their family responsibilities, reversely their family duties because of their work responsibilities. Especially, when it is considered that teaching profession is not limited to their school, it can be easier for teachers to disrupt work-family life balance. Teachers may have conflict between their work and family due to equitemporaneous roles in both sides. The role conflicts may provoke to more serious problems in teachers' private life. Teachers can experience tension, stress and burnout as a result of these situations. Work-family and family-work conflicts not only affect teachers and their families negatively, but also affect the quality of teaching. For such reasons, it has been considered to mitigate work-family and family-work conflicts of teachers working in educational organisations which have a great role in the advancement of future generations. The researcher has met no study in the educational organisations about the effects of psychological capital on the work-family and family-work conflicts which are the serious problems of our age. With this research, to diminish negative effects of work-family conflict which increases some negative attitudes such as tension, stress and fatigue, a psychological source which nourish positive thinking against living situations is presented (Mete et al., 2014; Rubab, 2017). The aim of this research is to elicit the relationship between psychological capital of teachers and work-family and family-work conflicts. These hypothesises below has been tested for this purpose: 
- H1: Teachers' psychological capital negatively influences workfamily conflict.

- H2: Teachers' psychological capital negatively influences familywork conflict.

In this research, correlational model has been used to larn whether variables have changed together or not, if there is change, their directions and levels (Büyüköztürk et al., 2012; Karasar, 2012). the connections between psychological capital of teachers and work-family and family-work conflicts have been construed in current study. To determine the effects of psychological capital on work-family and family-work conflicts, structural models have been created seperately for each one. Teachers working in primary, middle and high schools in Antakya district of Hatay in 2018-2019 educational year have effectuated the working universe of this study.

In this study, cluster sampling method from the sampling methods have been used in all cases where all groups in the universe have had the chance to be equal (Karasar, 2012). Primary, middle and high Schools in Antakya have been evaluated as a cluster and 49 schools have been picked out coincidentally. The researcher have apprised teachers about the aim of the study and research variables and then teachers have been provided to participate to the study voluntarily. Scales have been applied to 368 participants. And, data obtained from 22 teachers have been declared invalid because of some reasons such as filling the scales faultily and imprecisely. To sum up, data taken from 346 teachers have been included in the analysis.

The data of the study were obtained by means of "Psychological Capital Scale" to measure psychological scale, "Work-Family Conflict Scale" to measure the family conflict connected with work and "Family-Work Conflict Scale" to measure the work conflict connected with family.

Psychological Capital Scale: This scale has been improved by Luthans and others (2007) and adapted to Turkish by Çetin and Basım (2012). The scale consists of 24 items and four dimensions (optimism, psychological resilience, hope and self-efficacy). The four-dimensional factor structure of the original has been confirmed (Explained variance $=70.788 \%$, Bartlett 
$=0.000, \mathrm{KMO}=0.942, \chi^{2}=147.224, \mathrm{df}=48, \chi^{2} / \mathrm{df}=3.067, \mathrm{P}$-value $=0.000$, GFI: 0.930, IFI $=0.956, \mathrm{TLI}=0.939, \mathrm{CFI}=0.956, \mathrm{RMSEA}=0.077)$. Cronbach's Alpha Coefficient of the whole scale is 0.940 . Cronbach's Alpha Coefficient for four sub-dimensions : Optimism is 0.775 , psychological resilience is 0.807 , hope is 0.744 and self-efficacy is 0.902 .

Work-family life Conflict Scale: This scale has been enhanced by Netemeyer, Boles and McMurrian (1996) and transcribed to Turkish by Efeoğlu (2006). Work-family life conflict scale comprises of work-family conflict arising from work life and family-work conflict arising from family life. There are 5 items in every sub-scale to detect the conflict circumstances. Two dimensional factor structure has been confirmed in original form of the scale (Explained variance $=75.866 \%$, Bartlett $=0.000$, $\mathrm{KMO}=0.922, \chi^{2}=84.885, \mathrm{df}=33, \chi^{2} / \mathrm{df}=2.572, \mathrm{P}$-value $=0.000, \mathrm{GFI}: 0.954$, $\mathrm{IFI}=0.980, \mathrm{TLI}=0.973, \mathrm{CFI}=0.980, \mathrm{RMSEA}=0.068$ ). Cronbach's Alpha coefficient is 0.929 for this scale. Cronbach's Alpha coefficient is in that for two sub-scales : Work-famiy conflict is 0.928 , family-work conflict is 0.909 .

In this study; Structural Equation Modeling has been used to generate more successful results by taking into account measurement errors. Structural Equation Modeling consists of two parts as Confirmatory Factor Analysis and Path Analysis. Factor structures of each scales have been confirmed by means of Confirmatory Factor Analysis and it has been seen that they are compatible with research data in good levels. Then, the effects of psychological capital on work-family and family-work conflicts have been examined in separate structural models.

It has been noticed that in measuring model in this research that there is a statically meaningful connection with psychological capital and workfamily, family-work conflicts. And then, path analysises have been done for the effect of psychological capital on work-family and family-work conflicts in different models. It has been espied that psychological capital of teachers can diminish work-family and family-work conflicts. In other words, positive psychological conditions of the teachers, the responsibilities in the family preventing the fulfillment of the roles in the work and the responsibilities of the family to prevent the fulfillment of roles in the work contribute to be balanced and to be harmonious. 
If family roles are interfered with work or work roles are interfered with family responsibilities, psychological capital can help teachers to endure. Nominately, it has been got across that individuals can upload positive meaning to the affairs with the help of psychological capital.

\section{Kaynakça / References}

Akçay, V. H. (2012). Pozitif psikolojik sermayenin iş tatmini ile ilişkisi. Kahramanmaraş Sütçü İmam Üniversitesi İktisadi ve İdari Bilimler Fakültesi Dergisi, 2(1), 123-140.

Bandura, A. (1997). Self-efficacy: The exercise of control. New York: W. H. Freeman and Company.

Bayram, N. (2013). Yapısal eşitlik modellemesine giriş amos uygulamaları. Bursa: Ezgi Kitabevi.

Bradley, K. (2014). Educator's positive stress responses: Eustress and psychological capital. Unpublished doctoral dissertation. DePaul University, Chicago, United States.

Büyüköztürk, Ş., Çakmak, E. K., Akgün, Ö. E., Karadeniz, Ş. V. ve Demirel, F. (2012). Bilimsel araştırma yöntemleri. Ankara: PegemA.

Byrne, B. M. (2010). Structural equation modeling with AMOS. New York: Routledge.

Çetin, F. ve Basım, H. N. (2012). Örgütsel psikolojik sermaye: Bir ölçek uyarlama çalışması. Amme İdaresi Dergisi, 45(1), 121-137.

Çınar, E. (2011). Pozitif psikolojik sermayenin örgütsel bağlllıkla ilişkisi. Yayımlanmamış yüksek lisans tezi. Dokuz Eylül Üniversitesi, İzmir, Türkiye.

Çokluk, Ö. (2014). Örgütlerde tükenmişlik. (C. Elma ve K. Demir Ed.). Yönetimde çă̆das yaklaşımlar, uygulamalar ve sorunlar, içinde (s.117-143). Ankara: Anı Yayıncilik.

Demir, S. (2018). The relationship between psychological capital and stress, anxiety, burnout, job satisfaction and job involvement. Eurasian Journal of Educational Research, 75, 137-154. doi: 10.14689/ejer.2018.75.8

Dirzyte, A., Patapas, A., Smalskys, V., ve Udavıciüte, V. (2013). Relationship between organizational commitment, job satisfaction and positive psychological capital in Lithuanian organizations. International Journal of Business and Social Science, 12(4), 115-122.

Dirican, M. (2015). Psikolojik sermaye. (N. D. E. ÖzlerEd.).Örgütsel davranışta güncel konular içinde (ss. 453-484). Bursa: Ekin Yayınevi. 
Efeoğlu, E. İ. (2006). İş-aile yaşam çatışmasının iş stresi, iş doyumu ve örgütsel bağlllık üzerindeki etkileri: İlaç Sektöründe Bir Araştırma. Yayımlanmamış Doktora Tezi. Çukurova Üniversitesi, Adana.

Erkuş, A. ve Fındıklı, M. A. (2013). Psikolojik sermayenin iş tatmini, iş performansı ve işten ayrılma niyeti uzerindeki etkisine yönelik bir araştırma. İstanbul Üniversitesi İşletme Fakültesi Dergisi, 42(2), 302-318.

Greenhaus, J., ve Beutell, N. (1985). Sources of conflict between work and family roles. Academy of Management Review, 10(1), 76-88.

Güney, S. (2012). Örgütsel davranış. Ankara: Nobel Akademik Yayıncllık.

Gürbüz, S. (2014). Kişi-çevre uyumu, örgütsel sosyalizasyon ve iş dizaynı uygulamaları. (Ü. Siğri ve S. Gürbüz ed.), Örgütsel davranış, içinde (s.175215). İstanbul: Beta Yayınları.

Hock, R. R. (1988). Professional burnout among public teachers. Public Personel Management, 17(2), 167-189.

Hochwarter, W. A., Ferris, G. R., Perrewe, P. L., Witt, L. A., ve Kiewitz, C. (2001). A note on the nonlinearity of the age-job satisfaction relationship. Journal of Applied Social Psychology, 31(6), 1223-1237.

Karasar, N. (2012). Bilimsel araştırma yöntemi. Ankara: Nobel.

Karatepe, O. M., ve Karadas, G. (2014). The effect of psychological capital on conflicts in the work-family interface, turnover and absence intentions. International Journal of Hospitality Management, 43, 132-143.

Kline, R. B. (2011). Principles and practice of structural equation modeling. New York: The Guilford Press.

Kreitner, R., ve Kinichi, A. (2009). Organizational behaviour (9th ed.). New York: Mc Graw-Hill International Edition.

Luthans, F., Avey, J. B., Avolio, B. J., Norman, S.M., ve Combs, G. M. (2006). Psychological capital development: Toward a microintervention. Journal of Organizational Behavior, 27(1), 387-393.

Luthans, F., Avey, J. B., ve Patera, J. L. (2008). Experimental analysis of a webbased training intervention to develop positive psychological capital. Academy of Management Learning \& Education, 7(2), 209-221.

Luthans, F., Avolio, B.J., Avey, J.B., ve Norman, S.M. (2007). Positive psychological capital: Measurement and relationship with performance and satisfaction. Personnel Psychology, 60, 541-572.

Luthans, F., ve Youssef, C. M. (2004). Human, social and now positive psychological capital management: Investing in people for competitive advantage. Organizational Dynamics, 33(2), 143-160. 
Maddux, J. (2002). Self-efficacy: The power of believing you can. In (C.R. Synder and S.J. Lopez eds), Handbook of positive psychology (p. 277-287). New York: Oxford University Press.

Mete, M., Ünal, Ö. F., ve Bilen, A. (2014). Impact of work-family conflict and burnout on performance of accounting professionals. Procedia-Social and Behavioral Sciences, 131, 264-270.

Meydan, C. H. ve Şeşen, H. (2015). Yapısal eşitlik modellemesi:Amos uygulamaları. Ankara: Detay Yayıncilık.

Netemeyer, R. G., Boles, J. S., ve McMurrian, R. (1996). Development and validation of work-family conflict and family-work conflict scales. Journal of Applied Psychology, 81(4), 400-410.

Özkalp, E. ve Kırel, Ç. (2010). Örgütsel davranış. Bursa: Ekin Yayınevi.

Parasuraman, S., ve Simmers, C. A. (2001). Types of employment, work-family conflict and well-being: A comparative study. Journal of Organizational Behavior, 22(5), 551-568.

Paşamehmetoğlu, A. ve Yeloğlu, H. O. (2014). Motivasyon. (Ü. Siğri And S. Gürbüz Ed.). Örgütsel davranış, içinde (s.137-174). İstanbul: Beta Yayınları.

Robbins, S.P., ve Judge, T.A. (2012). Örgütsel davranış (Çeviri editörü: İ. Erdem). İstanbul: Nobel.

Rubab, U. (2017). Impact of work family conflict on burnout and workplace deviant behavior: Mediating role of stress. Jinnah Business Review, 5(1), 1-10.

Sen, C., ve Hooja, H. R. (2015). Psychological capital and work-life balance: A study on police officers. International Journal of Management and Social Sciences Research (IJMSSR), 4(7), 93-96.

Wang, Y., Liu, L., Wang, J., ve Wang, L. (2012). Work-family conflict and burnout among chinese doctors: The mediating role of psychological capital. Journal of Occupational Health, 54, 232-240

\section{Kaynakça Bilgisi / Citation Information}

Demir, S. (2019). Psikolojik sermaye ve iş-aile yaşam çatışması ilişkilerinin incelenmesi. OPUS-Uluslararası Toplum Araştırmaları Dergisi, 13(19), 557-576. DOI: 10.26466/opus. 563221 